Healthcare Profile:

The Ottawa Hospital Celebrates Green Success
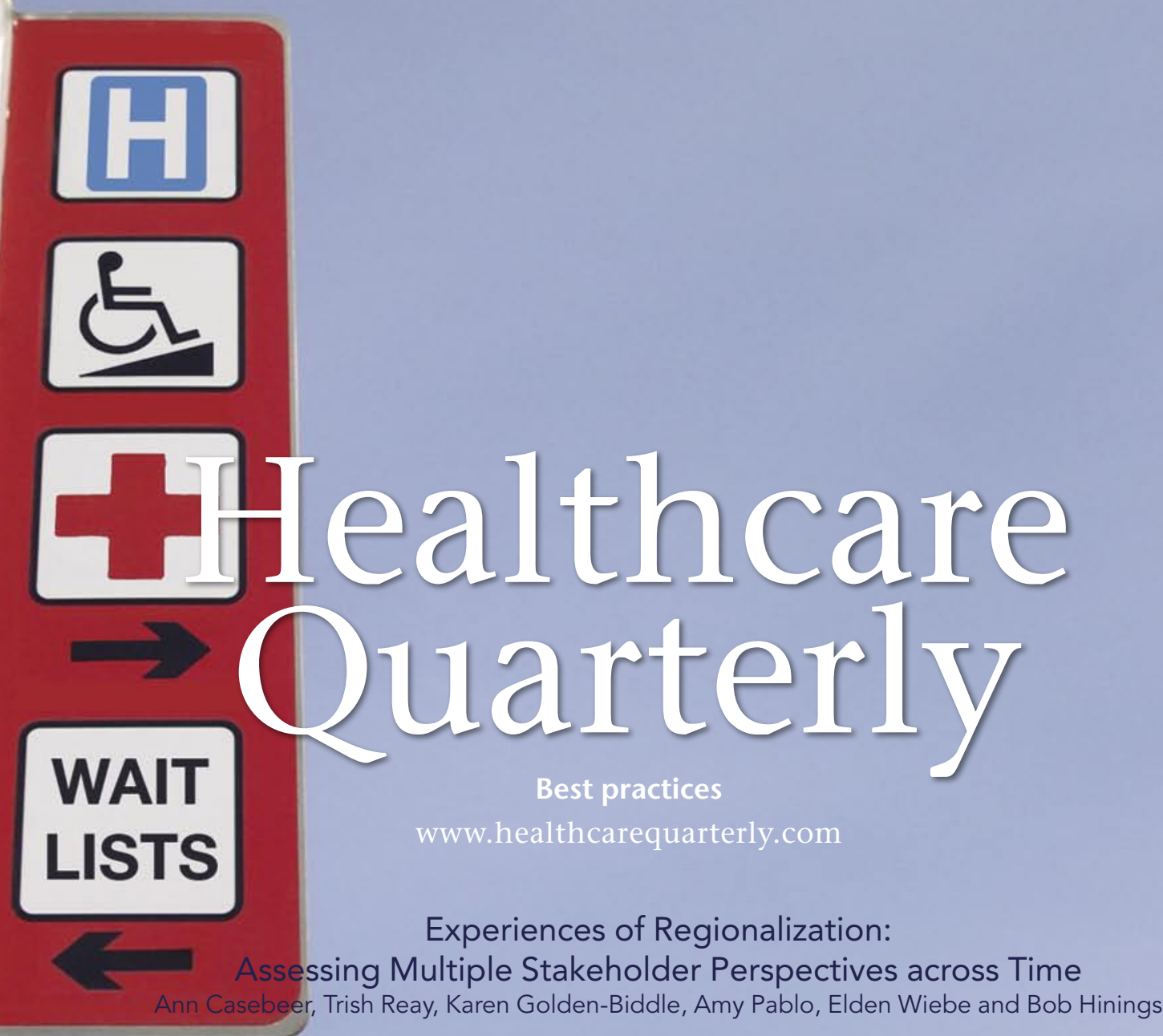

Towards Faster Treatment: Reducing Attendance and Waits at Emergency Departments

Longwoods Review

A Collaborative Approach to Building Capacity in Health Informatics

Francis Lau ElectronicHealthcare

Perspective • Ideas at Work • Online Case Study • Book Review • Futurethink 


\section{The Ottawa Hospital Celebrates Green Success}

Faris Rashid

$\mathrm{T}$ he Ottawa Hospital (TOH) is one of the largest healthcare organizations in Canada with more than 3.5 million square feet of space across three campuses - Civic, General and Riverside. With a vision to become "nationally recognized as the Academic Health Science Center of choice," $\mathrm{TOH}$ provides a full range of academic programs and services and operates a leading-edge Health Research Institute.

Building and sustaining financial strength is a key success factor for $\mathrm{TOH}$, and with this in mind, the facilities management department had concerns about the increasing annual energy budget of $\$ 14$ million. Improving building comfort, ensuring code compliance, reducing the environmental impact and managing utility risks were also key concerns. Consequently, the development of an energy-management plan was required to manage energy costs and improve building performance. To achieve this, TOH assessed the concept of "Performance Contracting," which offered a solution that would provide the necessary capital investment to allow for significant utility savings, while minimizing financial risk for the organization.

TOH supported the Performance Contracting approach, and through a competitive "Request for Proposal" process, Honeywell was selected to deliver an ambitious, long-term facility infrastructure renewal plan, designed to significantly improve the efficiency and quality of the hospital's buildings and systems while generating utility cost savings. The Honeywell Energy Conservation Program began in the winter of 2004 and was completed in summer 2005, investing approximately $\$ 17$ million in building infrastructure upgrades across TOH's three campuses. The investment provided $\mathrm{TOH}$ with a guaranteed utility savings of approximately $\$ 2.7$ million per year over a 15 -year period. Key components of the project included:

- Lighting retrofits at all three campuses

- Lighting upgrade of two parking garages

- New state-of-the-art Building Automation System covering approximately 5,500 points of control for all three campuses

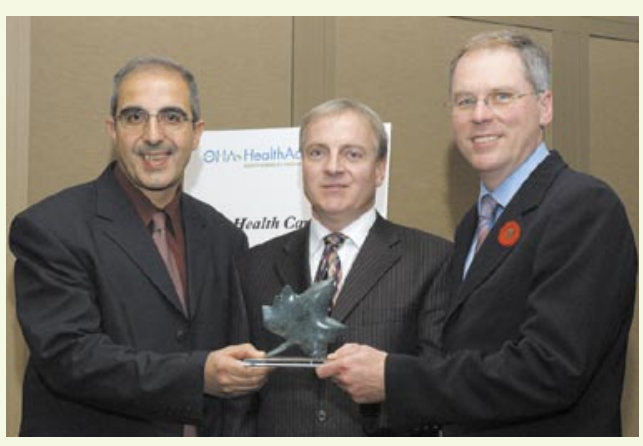

The Ottawa Hospital (TOH) received the Energy Efficiency award for the Green Health Care Awards at the OHA HealthAchieve2005 on November 1st.

/from left to right: Faris Rashid, P.Eng. -Energy Manager

$\mathrm{TOH}$, Brock Marshall, P.Eng. Director Engineering \&

Operations, TOH accepting the Energy Efficiency Award

from John Wilkinson, Parliamentary Assistant to the

Honorable Laurel C. Broten, Ontario's Minister of the

Environment
- Replacement of some chillers with more energy-efficient units and environmentally friendly "CFC free" chillers fow Sealing building envelops to reduce drafts and prevent energy leakage

Installation of water conserving fixtures and reduction in process water usage

Through the implementation of this program, $\mathrm{TOH}$ has reduced utility consumption of natural gas by $40 \%$, electricity by $18 \%$, steam by $23 \%$ and water by $5 \%$, resulting in annual savings of $\$ 2.7$ million. Mr. Brock Marshall, Director of Engineering Services at $\mathrm{TOH}$, realized the importance of controlling energy costs especially in volatile markets and has assigned an Energy Manager to monitor energy use, as well as find and evaluate additional ways to reduce energy consumption. "The savings guarantee is an important factor to the project as it allows $\mathrm{TOH}$ to manage any financial risk associated with the project. A lot of companies will tell us a figure of how much we can save in upgrading various building systems but most cannot guarantee these figures, which leaves the organization at risk when making an investment of this magnitude," said Mr. Marshall. 
The environmental impact of the project is also significant, reducing greenhouse gas emissions by 11,833 tonnes annually (equivalent to the need of 39,132 trees). The annual energy reduction is $184,279 \mathrm{GJ}$ or $0.62 \mathrm{GJ} / \mathrm{m}^{2}$. The economics of the project show a rate of return at $12 \%$ with cost-savings at $\$ 2,546,488$ for the total project cost at $\$ 17,068,531$. The lighting retrofit resulted in recycling of fluorescent tubes and magnetic ballasts, which totalled 9.8 tonnes glass, $123 \mathrm{~kg}$ aluminum, 154 $\mathrm{kg}$ phosphor and $1.02 \mathrm{~kg}$ mercury. The ongoing awareness program will continue to facilitate better understanding of the Energy Performance Contract among employees and the surrounding community. It was estimated that the employee awareness initiative saved $\mathrm{TOH} \$ 80$ thousand based on internal metering. Staff is more aware to report about leaking faucets, overcooling or overheating in their zones and also to make suggestions to save more energy. Other hospitals began to request information about similar projects in their hospitals. NRCan with OHA organized a meeting hosted at the Civic Campus to give more information about the incentive program and the use of Performance Contracting in case they have problems with financing. $\mathrm{TOH}$ contribution to the community and environment was greatly appreciated.

Additional benefits of the program:

1. The safety and engineering recommended levels for lighting, indoor air quality (temperature and humidity) will be improved and confirmed to comply with the Code after retrofitting and implementing the energy conservation measures. The result will be a more efficient response to building heating and cooling requirements and better staff and patient comfort.

2. $\mathrm{TOH}$ operators will receive training on the operation of new equipment.

3. Number of hours to complete maintenance will be reduced.

4. An ongoing Awareness Program will be provided to facilitate a better understanding of the Energy Performance Contract among hospital personnel, visitors and the surrounding community.

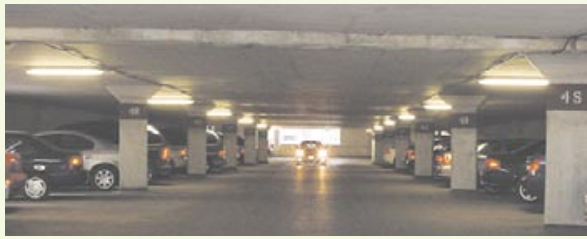

The lighting project included the garage lighting at the Civic and General Campuses. The old highpressure sodium fixtures were replaced with new T5 fluorescent fixtures that met the recommended illumination levels in healthcare facilities.
August 2005 was a significant milestone in the project when $\mathrm{TOH}$ and Honeywell held a staff celebration to mark the completion of the construction phase of the project. Enbridge Gas Distribution, Hydro Ottawa and Natural Resources Canada also participated in the celebration and contributed to the TOH staff energy awareness campaign. Peter Love, Ontario's Chief Energy Conservation Officer at Ontario Power Authority, was also present and said, "The program is an excellent example of how institutions can reduce their energy consumption and save on expenses, thereby lightening the load on our energy supply and on local taxpayers. The province encourages more public and private sector organizations to follow the hospital's lead." Mr. Love provided TOH with a Certificate of Recognition for their long-term commitment to conserving electricity in Ontario.

As part of the awareness program, $\mathrm{TOH}$ continues to participate in the National Health Care Energy Efficiency Awareness Week held each year during the first week of February. Honeywell supports this event at the three $\mathrm{TOH}$ campuses by promoting energy-efficiency with displays, contests, giveaways and the sharing of energy-efficiency and conservation material. This year's event focused on the "One-Tonne Challenge," encouraging hospital staff to reduce their personal greenhouse gas emissions by one tonne. Those who participated received a free compact fluorescent lightbulb to start them on their way to reducing energy at home. Hundreds stopped by to ask questions about this challenge and share ways they have been saving energy and water, both at home and at work.

As a result of the project's success, $\mathrm{TOH}$ was awarded the 2005 Energy Efficiency Award for Buildings, one of the Ontario Hospital Association's Green Health Care Awards. Hospital representatives accepted the award in November 2005 at the OHA HealthAchieve conference in Toronto.

\section{About the Author}

Faris Rashid, P.Eng. is the Energy Manager at The Ottawa Hospital. He can be contacted at: frashid@Ottawahospital.on.ca 